\title{
Profissão do lar: (des)valorizada, (não)reconhecida e (in)visível. até quando?
}

Household profession: (de)valued, (un)recognized and (in)visible. until when?

\author{
Marcos Vinicius Dalagostini Bidarte* \\ Carolina Freddo Fleck ${ }^{* *}$ \\ Elena Maria Billig Mello
}

\section{Resumo}

Este estudo tem como objetivos: (a) investigar quem são os sujeitos que abandonaram funções remuneradas no mercado de trabalho para o exercício da profissão do lar, analisando as principais razões para tal atitude e seus reflexos para as questões de gênero, domésticas e familiares, e (b) analisar a (in)visibilidade do trabalho doméstico não remunerado, o (auto)reconhecimento e a (des)valorização social e familiar desse trabalho percebida pelos profissionais do lar. Através de entrevistas, utilizando a história oral temática, realizadas com treze profissionais do lar, os resultados revelam que eles/as abandonaram o mercado de trabalho por diversas razões, estando relacionadas à idade, às situações sociais e conjugais, ao contexto econômico, à escolaridade e às relações de trabalho. O trabalho doméstico é percebido por eles/as como uma atividade, que além de não remunerada, é invisível e desvalorizada na esfera privada, tanto pela família quanto pela sociedade. Os porquês disso já são conhecidos. A pergunta que fica é: Até quando?

Palavras-chave: Gênero, Profissão do Lar, Trabalho Reprodutivo, Afazeres Domésticos, Atividades de Cuidado.

\begin{abstract}
The study purposes is: (a) investigate who are the subjects who left paid jobs in the labor market in order to become household professionals, by analyzing the main reasons for such an attitude and its reflections for gender, domestic and family issues, and (b) analyze the (in)visibility of unpaid domestic work, the (self)recognition and social and family (de)valuation of this work as perceived by household professionals. Through interviews, using the thematic oral history, carried out with thirteen household professionals, the results reveal that the interviewees abandoned the labor market for several reasons,

\footnotetext{
* Doutorando em Administração pela Universidade Federal do Rio Grande do Sul (UFRGS), Brasil. Contato: bidarte.vinicius@gmail.com

** Doutora em Administração. Professora Associada da Universidade Federal do Pampa (UNIPAMPA), Brasil. Contato: carolina.fleck@gmail.com

${ }^{* \star \star}$ Doutora em Educação. Professora Associada da Universidade Federal do Pampa (UNIPAMPA), Brasil. Contato: profelena@gmail.com
} 
related by age, by social and marital situations, by the economic context, by levels of education and by the working relationships. Domestic work is perceived, by the interviewees, as an unpaid, invisible and devalued activity of the private sphere, both by their families and by society. The reasons for this are known. The question that remains is: Until when?

Keywords: Gender, Household Profession, Reproductive Labor, Household Chores, Care Activities.

Fecha de recepción: Enero 2021

Fecha de aprobación: Junio 2021

\section{Introdução}

Em suas construções históricas, as sociedades ocidentais são caracterizadas pelas relações de poder e dominação, em que os comportamentos dos sujeitos são designados a partir do sexo considerado primordial, o do homem. O masculino dita posições e percepções. Por isso, reflexões sobre questões relacionadas a gênero perpassam distinções biológicas e necessitam ser entendidas também a partir de diferenças advindas do contexto histórico-cultural. $O$ ideário persiste: 0 de homem como superior, dominador da natureza, da família e da sociedade; e de mulher para corresponder às concepções da sua natureza, vinculadas às funções naturais da sexualidade e da reprodução. Têm-se aos homens o público, a rua, o trabalho produtivo e remunerado; às mulheres o privado, a casa, o trabalho reprodutivo e não remunerado. Como reflexo disso, homens e mulheres não ocupavam, e não ocupam posições iguais nas sociedades (Kergoat, 2003; Perrot, 1988; Saffioti, 1987; Sullerot, 1970).

Mundialmente, a participação da mulher no mercado de trabalho elevou-se durante o século $X X$, nas sociedades ocidentais, especialmente a partir da década de 1950, quando houve alterações demográficas e mudanças nos valores relativos aos seus papéis sociais (Sullerot, 1970). No Brasil, a participação feminina no mercado de trabalho saltou de $18 \%$ na década de 1970 para mais de 50\% no início do século XXI (Madalozzo, Martins \& Shiratori, 2010), podendo ser explicada por vários fatores econômicos, sociais, demográficos, educacionais, culturais e políticos. A partir da década de 1970, os movimentos políticos e sociais questionaram mais fortemente a divisão sexual do trabalho, consolidada desde a industrialização, e permitiram às mulheres brasileiras a saída da esfera privada para o exercício do trabalho remunerado na esfera pública, modificando a estrutura familiar e os padrões sociais e desencadeando uma releitura na divisão sexual dos papéis desempenhados por ambos os sexos (Bruschini, 1985, 1994, 1995, 1996). Essa releitura ganhou força com a proclamação da Década da Mulher, em 1975, pela Organização das Nações Unidas e com o início do movimento feminista no país, quando as mulheres buscaram liberdade e igualdade de tratamento e de direitos entre os sexos. 
Apesar dos avanços dos movimentos políticos e sociais das mulheres e do ingresso maciço delas no mercado de trabalho, a sociedade brasileira ainda possui uma percepção enraizada acerca da realização do trabalho doméstico, atribuindo-o às mulheres. Em 2004, do total da população feminina ocupada (34,8 milhões), aproximadamente $91 \%$ delas realizavam a dupla jornada de trabalho, dividindo seu tempo entre o trabalho e a casa. Entre os homens, o indicador mostrava-se bastante inferior ao delas, apenas $46 \%$ do total da população masculina ocupada (47,9 milhões). As mulheres ocupadas tinham uma jornada média semanal em afazeres domésticos mais que o dobro da observada para os homens (21,2 horas) (IBGE, 2014). Passada uma década, o total da população feminina e masculina ocupada cresceu (elas: 39,9 milhões; eles: 52,5 milhões); entretanto, a proporção de mulheres realizando a dupla jornada de trabalho diminuiu para $88 \%$, enquanto entre os homens a proporção praticamente se manteve (IBGE, 2014). As mulheres ocupadas continuam dedicando muito mais horas semanais aos afazeres domésticos e/ou às atividades de cuidados que os homens (elas: 18,5 horas; eles: 10,4 horas) (IBGE, 2020).

Em 2021, pouco mais de meia década depois, e passado um ano que o mundo enfrenta uma pandemia sanitária, com a COVID-19, o percentual de mulheres no mercado de trabalho caiu de $53,5 \%$ para $45,8 \%$, retirando do espaço público milhões de mulheres (especialmente porque os postos de trabalho que mais tiveram retração são de profissões associadas às mulheres) e recolocando-as na esfera privada (mais de $57 \%$ indicam que a sobrecarga associada às atividades do lar ficou vinculada a elas durante a pandemia ou na divisão a sobrecarga maior ficou com elas) (PNAD Contínua/IBGE, 2021). Os dados indicam que mesmo quando houve aumento da participação feminina no mercado de trabalho não necessariamente significou abandonar a realização de afazeres domésticos e atividades de cuidado e que a evolução e as manifestações sociais parecem não ter sido suficientes para que as convenções de gênero deixassem de estabelecer papéis e identidades para ambos os sexos.

Os indicadores estruturais do mercado de trabalho brasileiro, de 2015, demonstravam, de forma quantitativa, que do total da população economicamente ativa (105,2 milhões), cerca de 44,2\% eram mulheres e 55,8\% homens; e que do total da população não economicamente ativa (51,1 milhões), aproximadamente $69,5 \%$ são mulheres e 30,5\% são homens (IBGE, 2015). Mesmo que o país tenha experimentado uma melhora até 2018 - com 52,7\% do mercado de trabalho ocupado por mulheres (PNAD Contínua/IBGE, 2021) os indicadores da pandemia novamente levam os números para a casa dos 40\%, como foi apontado no parágrafo anterior. O indicador do total da população não economicamente ativa feminina permanece superior em 2,27 vezes ao mesmo indicador masculino, revelando a profunda conexão que possui com o trabalho reprodutivo. No entanto, de forma qualitativa, esses dados não são capazes de responder, por exemplo, quais são as razões pelas quais eles e elas não ingressam ou abandonam permanentemente ou temporariamente o mercado de trabalho brasileiro.

A respeito do fenômeno social do abandono de funções remuneradas no mercado de trabalho, a literatura nacional e internacional tem apresentado estudos mostrando que, geralmente, são as mulheres que tomam essa decisão pelas mais diversas razões - e 
muitas vezes por razões associadas à família e ao lar, conforme revelam diversos estudos nacionais (Bezerra \& Vieira, 2013; Bidarte, 2018; Bidarte, Fleck \& Mello, 2018; Bidarte \& Fleck, 2019; Bruschini, 1985, 1994, 1995, 1998, 2007; Bruschini et al., 2011; Madalozzo, Martins \& Shiratori, 2010; Melo \& Sabbato, 2011; Rocha-Coutinho, 2004; Saffiotti, 1987; Santos \& Diniz, 2011, 2018; Soares \& Sabóia, 2007; Soares, 2016) e internacionais (Batthyány, Genta \& Perrotta, 2017; Caetano-da-Silva, 2013; Calderón \& Campos-Ríos, 2013; Carrasco, 2005; Chovwen, 2007; Funk, Lang \& Osterhaus, 2005; Hewlett \& Luce, 2005; Ituma \& Simpson, 2009; Kabeer et al., 2012; Perticará, 2005; Sen, 1998; Sullerot, 1970; Sullivan \& Mainiero, 2008).

Considerando os achados de estudos anteriores, fica evidente que quem permanece exclusivamente no lar, acaba tornando-se o principal responsável pela realização do trabalho reprodutivo na esfera privada. Neste estudo, o termo "profissional do lar" é sinônimo para o termo "trabalhador/a do lar". É sobre seus ombros que recaem os afazeres domésticos, as atividades de cuidados físicos e psicológicos, a administração e conservação do lar, tarefas essas que consomem muita energia e grande parte do tempo, realizadas exclusivamente para a própria família, não recebendo remuneração pelo seu trabalho. Utiliza-se o termo "profissional do lar" em vez de "dona de casa", já que esse último possui, na maior parte das vezes, conotações estereotipadas negativas na sociedade brasileira. Com isso, busca-se valorizar e visibilizar esse trabalho reprodutivo, esse trabalho doméstico não remunerado e, ainda, desassociar a ideologia patriarcal que conserva a imagem de "dona de casa" como sendo o ideal de mulher, esposa e mãe e que não trabalha (Bidarte, 2018; Bidarte, Fleck \& Mello, 2018).

Apesar da intenção de desconstruir um estereótipo associado às mulheres, cabe considerar que existe a construção social da identidade da mulher e do homem e a delimitação de papéis femininos e masculinos e que esta ainda é enraizada na sociedade. Assim, assume-se, neste estudo, o postulado de que o fenômeno social da transição de sujeitos de funções remuneradas no mercado de trabalho para o exercício da profissão do lar ocorre mais intensamente sobre as mulheres do que sobre os homens. Nessa perspectiva, a adesão ao enclausuramento ao lar pelos sujeitos, especialmente mulheres, não pode ser simplesmente aceita e vista como algo natural, sem antes interrogar as condições que causaram tal adesão.

Diante disso, surgem questionamentos, como: Quem são os sujeitos que abandonam funções remuneradas no mercado de trabalho para o exercício da profissão do lar? Quais as principais razões que os levam a essa atitude? Quais os reflexos para as questões de gênero, domésticas e familiares? Seu trabalho doméstico é visível, reconhecido e valorizado no lar? Ou ao contrário? Nessa perspectiva investigativa, este estudo teve como objetivos: (a) investigar sujeitos que abandonaram funções remuneradas no mercado de trabalho para o exercício da profissão do lar, analisando as principais razões para tal atitude e seus reflexos para as questões de gênero, domésticas e familiares, e (b) analisar a (in)visibilidade do trabalho doméstico não remunerado, o (auto)reconhecimento e a (des)valorização social e familiar desse trabalho percebida pelos/as profissionais do lar. 
O presente estudo estrutura-se em cinco seções, além desta introdução que conta com aporte teórico. Na segunda seção, apresenta-se a metodologia utilizada. Na terceira, quarta e quinta seções apresentam-se as análises e discussões dos dados coletados, buscando elementos para responder os objetivos levantados, a partir de uma apresentação dos/as profissionais do lar entrevistados/as, o processo do abandono de uma função remunerada no mercado de trabalho para o exercício da profissão do lar pelos sujeitos entrevistados, identificando as principais razões para tal atitude, e analisando-as por gênero, seguido de questões problemáticas do trabalho doméstico e seus reflexos na vida dos sujeitos entrevistados. Na sexta seção, expõem-se comentários finais e aponta-se para sugestões de pesquisas futuras na área.

\section{Metodologia}

Considerando os objetivos da pesquisa, utilizou-se a história oral temática, principalmente por ser uma "forma de captação de experiências de pessoas dispostas a falar sobre aspectos de sua vida, mantendo um compromisso com o contexto social" (Meihy \& Ribeiro, 2011, p. 12). Durante a pesquisa, seguiram-se os seguintes procedimentos indicados por Meihy \& Ribeiro (2011): (i) planejamento da condução das gravações; (ii) respeito aos procedimentos da história oral temática; (iii) tratamento da passagem do código oral para o escrito; (iv) conferência da gravação e validação pelo entrevistado; (v) autorização para o uso; e (vi) análise.

Em razão de que os/as profissionais do lar são indivíduos que possuem pouca visibilidade social, não são encontrados/as facilmente e constituem uma população difícil de ser acessada (Bidarte, Fleck \& Mello, 2018), utilizou-se como técnica de seleção de sujeitos a bola de neve, apropriando-se de uma abordagem em cadeia (Flick, 2009), realizada na cidade de Santana do Livramento/Brasil, e, inclusive, alcançando sujeitos de outras localidades, como Santa Maria/Brasil e Rivera/Uruguai. A partir desse mapeamento, chegou-se a um total de treze profissionais do lar do sexo feminino (nove participaram efetivamente) e quatro do sexo masculino, contatados através de doze informantes.

Para as entrevistas, elaborou-se um roteiro temático, fundamentado a partir da revisão teórica. Sempre que possível, as entrevistas foram conduzidas de forma individualizada, evitando possíveis influências externas sobre as respostas e interrupções. Solicitou-se autorização para que o conteúdo do discurso fosse analisado e para que as falas fossem utilizadas, através do Termo de Consentimento Livre e Esclarecido (Creswell, 2010; Flick, 2009; Meihy \& Ribeiro, 2011). Cada entrevista teve duração aproximada de 1 hora.

Após os conteúdos dos documentos serem conferidos e legitimados pelos/as profissionais do lar entrevistados/as, procedeu-se com a leitura e análise deles. Os documentos foram analisados por meio da análise textual discursiva (Moraes \& Galiazzi, 2011), respeitando seu conjunto de procedimentos analíticos. Examinou-se o conjunto de 13 documentos (corpus da análise) em seus detalhes, fragmentando-os e destacando 
seus elementos constituintes, atingindo unidades de significado. Atribuiu-se uma identificação em código para cada corpus da análise, como, por exemplo, em uma citação com o código (Bruna:2:3), significa que é um registro do discurso da entrevistada de nome fictício Bruna, escrito segundo a resposta da pergunta de número 2, e 3 representa o número da unidade de significado de sua reflexão. O sinal de pontuação dois-pontos serve apenas para separar as informações. Na sequência, apresenta-se a análise e discussão dos dados coletados.

\section{Apresentação dos/as profissionais do lar entrevistados/as: alguns breves comentários}

As informações sociodemográficas dos/as entrevistados/as foram agrupadas e são apresentadas na Tabela 1. Destaca-se que as informações sobre os marcadores sociais "cor/raça" e "classe social" foram coletadas com base na auto declaração dos homens e das mulheres entrevistadas, ou seja, na declaração espontânea de como eles e elas se percebem em relação a esses marcadores.

O perfil sociodemográfico dos/as profissionais do lar entrevistados/as revela a predominância de mulheres, de cor branca, heterossexuais, casadas, com 9 a 11 anos de estudo, moradoras urbanas, pertencentes à classe social média, com idade média de 44 anos, com composição familiar na maioria de 3 integrantes e com número de filhos/as na maioria de 2. É importante mencionar que, ao utilizar-se a bola de neve como técnica de seleção dos sujeitos entrevistados, houve uma tendência de indicação entre os/as profissionais do lar pertencentes à mesma realidade socioeconômica, o que, de certa forma, é esperado dado a sua abordagem em cadeia. Entretanto, para acessar diferentes realidades socioeconômicas sugere-se outros estudos na temática com diferentes abordagens metodológicas.

\section{Tabela 1 - Perfil sociodemográfico dos profissionais do lar entrevistados}

\begin{tabular}{|c|c|c|c|c|c|c|c|}
\hline $\begin{array}{l}\text { Profissional } \\
\text { do Lar }\end{array}$ & $\begin{array}{l}\text { Cor / } \\
\text { Raça }\end{array}$ & $\begin{array}{c}\text { Escolaridade } \\
\text { (anos de estudo) }\end{array}$ & $\begin{array}{c}\text { Estado } \\
\text { civil }\end{array}$ & $\begin{array}{l}\text { Classe } \\
\text { social }\end{array}$ & $\begin{array}{l}\text { Idade } \\
\text { (anos) }\end{array}$ & $\begin{array}{c}\text { Composição } \\
\text { familiar }\end{array}$ & Filhos \\
\hline \multicolumn{8}{|c|}{ Mulheres } \\
\hline Bruna & Branca & 9 a 11 anos & Solteira & Baixa & 45 & 3 & 2 \\
\hline Pâmela & Branca & 12 anos ou mais & Solteira & Média & 35 & 3 & 2 \\
\hline Cristina & Branca & 12 anos ou mais & Solteira & Baixa & 33 & 5 & 3 \\
\hline Heloísa & Branca & 9 a 11 anos & Casada & Média & 55 & 4 & 3 \\
\hline Eliana & Branca & 9 a 11 anos & Casada & Média & 59 & 3 & 4 \\
\hline Denise & Preta & 12 anos ou mais & Casada & Média & 29 & 3 & 1 \\
\hline Valéria & Preta & 12 anos ou mais & Casada & Baixa & 57 & 3 & 2 \\
\hline Rosa & Branca & 9 a 11 anos & Casada & Média & 46 & 4 & 2 \\
\hline Márcia & Branca & 12 anos ou mais & Divorciada & Média & 56 & 2 & 2 \\
\hline \multicolumn{8}{|c|}{ Homens } \\
\hline Caio & Preta & 5 a 8 anos & Solteiro & Baixa & 33 & 4 & 1 \\
\hline Gabriel & Branca & 12 anos ou mais & Solteiro & Média & 56 & 2 & - \\
\hline Diego & Branca & 12 anos ou mais & Casado & Média & 32 & 4 & 2 \\
\hline Eduardo & Branca & 12 anos ou mais & Solteiro & Média & 42 & 4 & 2 \\
\hline
\end{tabular}

Fonte: Elaborada pelo autor e pelas autoras de acordo com dados da pesquisa 
A Tabela 1 revela um resultado que confirma a hipótese inicialmente assumida neste estudo: predomínio de mulheres que abandonaram uma função remunerada no mercado de trabalho para o exercício da profissão do lar. As razões para tal atitude serão discutidas na seção a seguir. Entretanto, esse resultado, ainda que limitado ao cenário da investigação, reforça evidências de outras fontes do porquê as mulheres apresentarem níveis de ocupação menores que os dos homens. Sobre isso, de acordo com dados do IBGE (2014), reforçados pelos primeiros dados apurados durante a pandemia referentes a estes índices (PNAD Contínua/IBGE, 2021), de cada 100 mulheres na posição de pessoas de referência ou na posição de cônjuge, apenas 53 afirmaram estar ocupadas, enquanto em relação aos homens, cerca de 81 declararam estar ocupados. Isso mostra que a condição da mulher na família não parece alterar o seu ingresso no mercado de trabalho brasileiro.

Sobre a escolaridade, com exceção de um dos homens, os níveis educacionais são semelhantes e na média aproximam-se pelo menos da conclusão do ensino médio ou acesso ao ensino superior; também semelhantes à média nacional, que é de 9,3 anos (IBGE, 2010, 2016). Ao considerar a cor, são observados, no segmento de homens brancos entrevistados, níveis mais altos de escolaridade em relação ao conjunto de homens pretos entrevistados; e no segmento das mulheres brancas entrevistadas, na maioria dos casos, níveis mais baixos ou iguais de escolaridade em relação ao conjunto de mulheres pretas entrevistadas. Os resultados sobre as mulheres e os homens entrevistadas/os são corroborados pelo último Censo Demográfico realizado pelo IBGE (2010), o qual revelou que os segmentos historicamente mais desfavorecidos em relação ao acesso à educação (mulheres e pessoas de cor preta ou parda) apresentaram níveis mais altos de escolaridade em relação aos segmentos historicamente mais favorecidos (homens e pessoas de cor branca).

Em relação à idade, há maior presença de mulheres na faixa etária de 30 a 49 anos que se voltaram à profissão do lar, assim como na faixa etária de 50 anos ou mais. Mulheres que vivenciaram por um tempo o mercado de trabalho, e que, no auge da faixa etária considerada economicamente ativa, mudaram sua profissão. Sobre o tamanho da família, os indicadores de fecundidade e de número de pessoas na família no Brasil estão em queda desde os anos 2000 (IBGE, 2016). O número de filhos e de pessoas na família dos/as entrevistados/as apresentaram variação superior à média nacional, que é de 1 a 2 filhos/as e de 2 a 3 integrantes. Isso pode estar relacionado com a renda familiar mensal das famílias, o nível de escolaridade e, especialmente, com a idade, tendo em vista que algumas entrevistadas constituíram sua família antes deste período.

É notável a predominância do arranjo familiar composto por casais heterossexuais com filhos/as, arranjo esse normalmente relacionado à noção de família pela sociedade tradicional. Na composição desse arranjo familiar, aparece a presença do homem como a pessoa de referência, isto é, pessoa responsável pela unidade familiar (Bruna, Pâmela, Cristina, Heloísa, Eliana, Gabriel, Denise, Valéria, Rosa), mas também a presença da mulher como a pessoa de referência (Caio, Diego, Eduardo), desvinculando daquele modelo patriarcal e tradicional de família. Cabe a ressalva de que nesse arranjo familiar está havendo um aumento na proporção de mulheres como a pessoa de referência (2004: 
Revista Punto Género N ․ํ 15. Junio de 2021

ISSN 0719-0417 / 47-69

3,6\%; 2015: 22,5\%) e uma diminuição na proporção de homens como a pessoa de referência (2004: 67,7\%; 2015: 53,9\%). Uma das razões é o crescimento no apontamento da mulher como a pessoa de referência na unidade familiar, seja por receber maiores rendimentos médios no trabalho que o marido, seja por ser a única pessoa provedora econômica da família (IBGE, 2015, 2016), entre outros fatores.

\section{Do mercado de trabalho para a profissão do lar: quais as razões para tal atitude?}

Cada processo de abandono de uma função remunerada no mercado de trabalho para o exercício da profissão do lar foi analisado de forma individual, identificando as razões para tal atitude; posteriormente, considerações acerca do fenômeno social investigado foram realizadas para o grupo de profissionais do lar entrevistado, separandoas por gênero.

Classificadas em ordem de importância decrescente e por gênero, as razões de abandono do mercado de trabalho mencionadas pelas mulheres entrevistadas foram: filhos pequenos, maternidade, marido, familiar idoso e/ou doente, injustiças e aborrecimentos no emprego, desemprego, sentimento de saudade da família e dupla jornada de trabalho; e pelos homens entrevistados foram: desemprego, filhos pequenos, mudança de cidade, familiar idoso e doente, sentimento de saudade da família, elevado custo de vida na capital e atrasos no pagamento de salário (Tabela 2). Essas razões se distinguem entre os/as profissionais do lar entrevistados/as pela idade, pelas situações sociais e conjugais, pelo contexto econômico, pela escolaridade, pelas relações de trabalho e também por gênero. São razões distintas, às vezes similares, com diferentes implicações sobre as diversas esferas da vida dos/as entrevistados/as.

Tabela 2 - Razões do abandono do mercado de trabalho pelos/as profissionais do lar entrevistados/as

\begin{tabular}{|c|c|c|}
\hline $\begin{array}{l}\text { Profissional do } \\
\text { Lar }\end{array}$ & $\begin{array}{l}\text { Imposição ou } \\
\text { Escolha? }\end{array}$ & Principais razões \\
\hline \multicolumn{3}{|r|}{ Mulheres } \\
\hline Bruna & Escolha & Maternidade, filho pequeno \\
\hline Pâmela & Escolha & Maternidade, filhos pequenos \\
\hline Cristina & Imposição & Filhos pequenos; marido \\
\hline & Imposição & Marido \\
\hline Heloísa & Escolha & $\begin{array}{c}\text { Aborrecimentos no emprego; idade avançada do marido; } \\
\text { sentimento de saudade da família }\end{array}$ \\
\hline Eliana & $\begin{array}{l}\text { Escolha } \\
\text { Imposição }\end{array}$ & $\begin{array}{c}\text { Injustiças e aborrecimentos no emprego } \\
\text { Desemprego }\end{array}$ \\
\hline Denise & Escolha & Maternidade, filho pequeno \\
\hline Valéria & Escolha & Familiar doente \\
\hline Rosa & $\begin{array}{l}\text { Imposição } \\
\text { Escolha }\end{array}$ & $\begin{array}{l}\text { Desemprego } \\
\text { Filho pequeno e doente }\end{array}$ \\
\hline Márcia & $\begin{array}{l}\text { Escolha } \\
\text { Escolha }\end{array}$ & $\begin{array}{l}\text { Maternidade, filhos pequenos } \\
\text { Dupla jornada de trabalho; filhos; familiar doente }\end{array}$ \\
\hline
\end{tabular}




\section{Homens}

\begin{tabular}{ccc} 
Caio & Escolha & $\begin{array}{c}\text { Elevado custo de vida na capital; mudança de cidade; } \\
\text { sentimento de saudade da família }\end{array}$ \\
Gabriel & Imposição & $\begin{array}{c}\text { Desemprego } \\
\text { Imposição }\end{array}$ \\
Diego & Escolha & Atrasos no pagamento de salário; mudança de cidade \\
Eduardo & Imposição & Desemprego \\
Imposição & Desemprego \\
\hline
\end{tabular}

Fonte: Elaborada pelo autor e pelas autoras de acordo com dados da pesquisa

Em relação às mulheres entrevistadas, verificou-se que, nos casos de escolha, a maternidade e filhos/as pequenos/as foram as principais razões pelas quais elas abandonaram o mercado de trabalho; e, nos casos de imposição, o desemprego e o marido foram as principais razões apontadas. Por outro lado, em relação aos homens entrevistados, nos casos de escolha, a mudança de cidade foi mencionada como a principal razão para estarem em casa; e, nos casos de imposição, o desemprego foi a principal razão mencionada. A análise dessas principais informações, ao considerar a desagregação imposição/escolha, revelou que os homens e as mulheres entrevistados/as abandonaram o mercado de trabalho por razões completamente distintas, possuindo como razão comum apenas o desemprego (Tabela 2).

É notável a presença de entrevistados/as, como Heloísa, Eliana, Diego, Rosa, Márcia e Eduardo, que abandonaram, ao longo de suas vidas, mais de uma vez o exercício de uma função remunerada no mercado de trabalho para permanecerem em casa. Nesses casos, o abandono se deu ora por escolha, ora por imposição, sendo que as razões para essas atitudes foram distintas, geralmente com implicações sobre as diversas esferas de suas vidas (Tabela 2).

Considerando as informações contidas nos discursos dos/as profissionais do lar entrevistados/as sobre o fenômeno social investigado, percebeu-se que o desejo de ser mãe, de cuidar dos filhos em tempo integral, faz parte de uma realização pessoal; que os custos com a contratação do serviço de uma pessoa trabalhadora para os cuidados infantis ou uma escola em tempo integral não compensaria a ausência em casa, revelando que a escolha repousa sobre uma situação social precária; que o apoio do/a cônjuge e/ou a condição financeira favorável permitiram a concretização de um projeto familiar, no qual cada um/a deles/as acabou reafirmando os papéis sociais atribuídos historicamente aos homens e às mulheres, sem necessariamente tornar o desejo de ter filhos/as e formar família em uma reflexão que englobasse futuro profissional (fora do lar) de ambos; que a opressão marital a que as mulheres ainda estão sujeitas implica na incapacidade delas expressarem sua decisão de adesão ao lar; que a necessidade de zelo por parte de algum familiar implicou na dedicação integral às atividades de cuidados; que o desemprego revelou as dificuldades impostas pelo mercado de trabalho, 
preocupante especialmente para os/as que estão há bastante tempo fora desse, relacionando-as à idade, à cor, à escolaridade e às experiências laborais.

Cabe ressaltar que seis das nove mulheres entrevistadas informaram que, antes ou após o nascimento de seus/as filhos/as, optaram por deixar o mercado de trabalho para ficar em casa, realizando as atividades de cuidados infantis, visto que a maternidade constitui um ponto importante do projeto de suas vidas. A decisão tomada por elas foi respaldada devido ao cônjuge estar empregado naquele momento e/ou à condição financeira familiar favorável. Essas mães não quiseram "transferir" as funções maternas para outras pessoas, pois o desejo de ter filhos/as e cuidar deles/as fazia parte de uma realização pessoal, sentindo-se protagonistas na continuidade da vida. Para elas, cuidar pessoalmente dos/as filhos/as legitima suas permanências em casa, justificando todo tipo de sacrifício.

Entretanto, a construção social desse papel feminino, apoiado nas condições biológicas da mulher, deve ser problematizado. Segundo o pensamento machista, é "natural" que a mulher se dedique aos/às filhos/as, que fique em casa. Torna-se, então, clara a atribuição das tarefas de cuidado a ela (Bidarte, Fleck \& Mello, 2018; Bruschini, 1985, 1995; Rocha-Coutinho, 2004; Saffioti, 1987; Santos \& Diniz, 2011, 2018).

Os resultados deste estudo contrapõem as afirmações realizadas por Bruschini de que "as mães ingressam cada vez mais no mercado de trabalho e não saem dele por causa dos filhos" (1995, p. 39) e também por Costa, de que "a maternidade não afasta mais as mulheres do trabalho, continuam ativas na fase reprodutiva" (2014, p. 8). Cabe mencionar que essas afirmações dizem respeito às análises sobre o comportamento do mercado de trabalho brasileiro considerando, dentre outras, a relação entre maternidade e atividade econômica feminina, a partir de dados estatísticos.

De fato, estudos de gênero têm mostrado que muitas mulheres permanecem no mercado de trabalho após o nascimento dos/as filhos/as, devido à necessidade de obter rendimentos, sobretudo no caso das famílias pobres ou das chefiadas por mulheres; à renda familiar mensal favorável; à disponibilidade de serviços sociais e de equipamentos de consumo coletivo públicos e particulares, como creches, pré-escolas e escolas em tempo integral (Bruschini, 1985, 1995, 1998; Ricoldi, 2010; Saffioti, 1987; Soares, 2016; Soares \& Sabóia, 2007). No entanto, nos casos deste estudo, a tarefa de criação, cuidados e socialização dos/as filhos/as ainda permanece tradicionalmente feminina, ocupando lugar de destaque nas responsabilidades das mulheres e fazendo com que abandonem, permanente ou temporariamente, o mercado de trabalho. Esses achados, portanto, refletem a realidade dos/as profissionais do lar entrevistados/as, não a do Brasil.

Outra razão do abandono do mercado de trabalho pelas mulheres entrevistadas foi devido aos maridos (Tabela 2). No caso de Cristina, circunscrita a uma situação precária, ela deixou o mercado de trabalho para cuidar dos/as filhos/as, sendo sua ação constantemente incentivada por seu marido. Ela comenta que o desejo de seu marido era de que ela permanecesse em casa, cuidando dos/as filhos/as e dos afazeres domésticos, enquanto ele oferecia o sustento econômico à família. Isso reflete, além dos papéis sociais tradicionais, uma forma de exercer controle do homem sobre a mulher. Já no caso 
de Heloísa, em razão da idade avançada de seu marido, a questão era quem cuidaria dele. Como esposa, esperava-se que ela fosse a principal responsável pelas atividades de cuidados em relação a ele. Observa-se uma mistura de questões relacionadas à obrigação, ao dever e ao papel feminino nos afazeres domésticos e nas atividades de cuidados.

Ainda considerando as informações da Tabela 2, é notável que a transição de uma função remunerada no mercado de trabalho para o exercício da profissão do lar deu-se, na maioria dos casos, por fatores familiares, como filhos/as pequenos/as, familiar idoso/a e/ou doente e marido. Esses resultados são corroborados por diversos estudos nacionais (Bezerra \& Vieira, 2013; Bidarte, 2018; Bidarte, Fleck \& Mello, 2018; Bruschini, 1985, 1994, 1995, 1998, 2007; Bruschini et al., 2011; Madalozzo, Martins \& Shiratori, 2010; Melo \& Sabbato, 2011; Rocha-Coutinho, 2004; Saffiotti, 1987; Santos \& Diniz, 2011, 2018; Soares \& Sabóia, 2007; Soares, 2016). Ao comparar esses resultados com outros países, percebe-se que os fatores familiares são os mesmos que levam as mulheres a abandonarem o mercado de trabalho, por exemplo, na Angola (Caetano-da-Silva, 2013), no Chile (Perticará, 2005), na Espanha (Carrasco, 2005), nos Estados Unidos (Hewlett \& Luce, 2005; Sullivan \& Mainiero, 2008), na Índia (Kabeer et al., 2012; Sen, 1998), no México (Calderón, \& Campos-Ríos, 2013; Funk, Lang \& Osterhaus, 2005), na Nigéria (Chovwen, 2007; Ituma \& Simpson, 2009), no Paquistão (Kabeer et al., 2012), e no Uruguai (Batthyány, Genta \& Perrotta, 2017). É notório que a tradição social e os papéis sociais atribuídos historicamente às mulheres ainda se fazem presentes em diversas sociedades, com níveis de desenvolvimento social e econômico distintos.

\section{Profissão do lar: (des)valorizada, (não)reconhecida e (in)visível. Até quando?}

$\mathrm{Na}$ perspectiva dos/as entrevistados/as se reconhecerem e serem reconhecidos/as como um/a profissional do lar, de um lado, há o grupo que se reconhece (Bruna, Caio, Eliana, Gabriel, Denise, Valéria, Márcia, Eduardo) e sente-se reconhecido/a pela família (Bruna, Caio, Eliana, Gabriel, Diego, Denise, Valéria, Márcia, Eduardo) e pela sociedade (Bruna, Caio, Eliana); e de outro, há o grupo que não se reconhece (Pâmela, Cristina, Heloísa, Diego, Rosa) e não se sente reconhecido/a pela família (Pâmela, Cristina, Heloísa, Rosa) e pela sociedade (Bruna, Pâmela, Cristina, Heloísa, Gabriel, Diego, Denise, Valéria, Rosa, Márcia, Eduardo), como pode ser observado nas unidades de significado apresentadas a seguir.

Em alguns discursos dos/as profissionais do lar entrevistados/as aparece que quem realiza o trabalho no âmbito doméstico ainda está sujeito ao preconceito por parte da família e da sociedade. Há menção de que pessoas realizam questionamentos indelicados e comentários maldosos sobre a permanência deles/as na esfera privada. Esse preconceito cultural e histórico contribui para que os/as entrevistados/as não se reconheçam como profissionais do lar, além de desvalorizar seu trabalho doméstico e os/as invisibilizar como sujeitos. Problematiza-se como esses questionamentos e comentários podem afetar suas vidas, causando-lhes sentimentos negativos, 
comprometendo suas saúdes mentais, uma vez que permanecem grande parte do dia sozinhos no lar.

"Eu sou uma profissional do lar. Sou reconhecida pela família, mas muitas vezes não sou reconhecida pela sociedade. Tem sempre aquela pessoa que chega e fala: 'Ah, tu não trabalha.' ou 'Tu só vive em casa!'. Só que eu estando em casa eu trabalho mais do que na rua." (Bruna:7:2);

“Eu não me sinto, não me reconheço como uma profissional do lar. (...) Eu não me vejo ofendida, mal vista, nem nada, até porque eu não estou nem aí para o que as pessoas da minha família ou em geral falam ou pensam. (risos)" (Pâmela:7:3);

"Eu me reconheço como um cara do lar, porque eu sei o que eu tô fazendo, eu tô cuidando da minha casa e da minha família. A minha família me reconhece como um cara do lar, e tem muita gente que me reconhece também." (Caio:7:1);

"Eu fico pensando sozinha em casa sobre isso. (com a mão no queixo, pensando) É complicado tu te enxergar como uma profissional do lar, de ser do lar. (...) Ficar só em casa, com os filhos, arrumando as coisas da casa. É difícil de tu se reconhecer, de ter consciência daquilo que tu tá fazendo, mais ainda é tu ser reconhecida. Né?" (Cristina:7:1);

"Eu não me vejo como profissional do lar. Eu só acho que cumpro com as minhas obrigações, sabe? (...) Os meus amigos entram em contato comigo e dizem: 'E aí, vagabundo!' ou ainda 'E aí, tchê! Tá trabalhando ou não tá?' Eles não entendem que eu tô cuidando dos meus filhos e da minha casa. Eles me veem como desempregado, não como profissional do lar." (feição de tristeza) (Diego:7:3);

"A pessoa que tá em casa limpando (apontando para si mesma), passando, varrendo, esfregando o chão não é reconhecida por ninguém! (balançando a cabeça negativamente)" (Valéria:7:1);

“Eu não me reconheço. (...) Eu me sinto, às vezes, meio alienada, porque o marido sai, vive uma coisa fora de casa, e eu só no meu mundinho dentro de casa. (feição de tristeza) (...) E também não sinto esse reconhecimento.” (Rosa:7:2).

A percepção de (des)valorização do trabalho doméstico pelos/as profissionais do lar entrevistados/as gerou visões díspares. No entanto, a maioria dos discursos realizou menção ao trabalho doméstico como uma atividade não remunerada, invisível e desvalorizada na esfera privada, tanto pela família quanto pela sociedade. Cabe considerar que se o trabalho doméstico é desvalorizado, invisibilizado, quem o realiza também é, o que revela a dupla desvalorização, invisibilização. Isso pode ser observado nas unidades de significado apresentadas a seguir.

Ao desagregar a informação segundo sexo, idade, cor, escolaridade e classe social, observa-se duas coisas. Primeiro, mulheres como Bruna, Cristina, Heloísa, Eliane, Valéria e Rosa representam a maioria das entrevistadas que compartilha a experiência de desvalorização do trabalho doméstico e realiza menção à invisibilidade de seu trabalho por suas famílias. Isso pode ser explicado pelo fato de a sociedade capitalista e patriarcal 
ter fundamentado o papel da mulher na reprodução biológica e na realização dos afazeres domésticos, definindo, assim, seu lugar na esfera privada (Kergoat, 2003; Melo, Considera \& Sabbato, 2016; Saffioti, 1969, 1987). Segundo, todos os homens entrevistados mencionaram que seu trabalho doméstico é valorizado por suas famílias. Isso pode ser observado por não ser o destino "natural" do sexo. Caio, Gabriel, Diego e Eduardo são homens que não compartilham a experiência de desvalorização e invisibilidade de seu trabalho doméstico na esfera privada, e uma das razões para isso está na construção sociocultural, que atribui mais valor às atividades masculinas do que às femininas (Kergoat, 2003; Melo \& Castilho, 2009).

"O trabalho de casa é desvalorizado totalmente! Ninguém vê o que tu faz em casa! É invisível! Ninguém nota que tu faz as coisas, só vão notar no dia que tu não fizer! (entonação de voz elevada) (...) É muito raro alguém de dentro ou fora de casa te dizer: 'Nossa! Que rico cheirinho de casa limpa!'. Agora, se tem algo sujo, já falam: 'Bah! Que sujeira!' É só isso que todo mundo enxerga." (Bruna:8:1);

"O meu trabalho doméstico, que faço dentro da minha casa, é bem valorizado pela minha família. Pela sociedade, em geral, eu acho que não, porque ela não vê o que eu faço dentro de casa." (Caio:8:1);

"É um trabalho ignorado, invisível! Ou o trabalho é invisível ou a pessoa que faz é invisível! (risos) Eu acho que os membros da família não percebem o meu trabalho (suspiro), por mais que a gente seja próximo, que a gente converse. (feição de tristeza)." (Heloísa:8:1);

"Pela minha família vejo que é valorizado, mas não pela sociedade." (Diego:8:1);

"O trabalho que a gente faz em casa não é valorizado, não tem o valor que deveria ter (ênfase da entrevistada nas palavras em destaque), tanto pela família quanto pela sociedade, mas principalmente pela sociedade, porque ela não valoriza o trabalho do homem e principalmente da mulher que fica em casa." (Valéria:8:1).

O trabalho doméstico, muitas vezes, somente ganha visibilidade quando algum afazer (ainda) não foi realizado, como o almoço que não ficou pronto no horário, o/a filho/a que não foi banhado/a, o animal de estimação que não foi alimentado, a roupa que não foi lavada, o pó sobre os móveis que não foi tirado, o chão que não foi varrido, o lixo que não foi recolhido. Não se enxerga o que foi feito, apenas o que ainda não foi feito ou que deixou de ser feito. A desordem é visível, a ordem é invisível.

Em alguns discursos, há preocupações com relação ao desrespeito e à desvalorização familiar do trabalho doméstico, que os/as entrevistados/as atribuem ao fato de realizar um trabalho improdutivo. Mas quais as razões para não valorizar um trabalho que possui grande importância para o bem-estar dos membros da família e da sociedade? Por que não valorizar o banheiro cheiroso? O quarto arrumado? A cozinha limpa? A sala organizada? A roupa lavada, passada e guardada? A refeição preparada? A criança alimentada e banhada? O familiar idoso e/ou doente assistido? Os animais domésticos cuidados? 
Diante dessas perguntas, a literatura tem apontado para diversas respostas. Parte da desvalorização do trabalho doméstico pela sociedade e pelos membros da família deve-se ao fato de não ser remunerado e de não contribuir monetariamente para o orçamento familiar mensal; a outra parte está atrelada a um papel secularmente atribuído às mulheres como uma espécie de "obrigação" (Bruschini, 1985, 1998, 2006; Bidarte, Fleck \& Mello, 2018; Melo, Considera \& Sabbato, 2016; Melo \& Castilho, 2009; Saffioti, 1969, 1987; Santos \& Diniz, 2011, 2018). Entretanto, é essencial que se reconheça que é sobre os ombros das mulheres que recaem as responsabilidades de cuidar dos membros da família que compõem o mercado de trabalho, daqueles/as que recebem remunerações e adquirem bens e serviços de consumo (Saffioti, 1969; Santos \& Diniz, 2018).

Cabe ainda mencionar que o trabalho doméstico, quando exercido por um membro da própria família, não é considerado trabalho no contexto do sistema capitalista devido à sua inadequação ao modelo de trabalho vigente, que explora a classe trabalhadora e acumula capital (Marx, 1988). Deste modo, a noção de trabalho elaborada por esse sistema acaba intensificando as desigualdades entre mulheres e homens no mercado laboral, atribuindo menor valor ao trabalho reprodutivo, doméstico e feminino, e maior valor ao trabalho produtivo, mercantil e masculino (Kergoat, 2003; Melo \& Castilho, 2009). É justamente por essas razões que alguns/mas entrevistados/as, especialmente mulheres, não se reconhecem como profissionais do lar, por não estarem no mercado de trabalho, realizando atividades produtivas, mercantis, remuneradas.

A principal renda familiar mensal provém, na maioria dos casos, da realização do trabalho do/a cônjuge (Bruna, Caio, Cristina, Heloísa, Eliana, Diego, Denise, Valéria, Rosa, Eduardo); e, em alguns casos, do trabalho de algum/a filho/a (Eliana, Márcia), da aposentadoria (Gabriel) ou da pensão alimentícia (Pâmela). De forma geral, o homem, no arranjo familiar composto por casal heterossexual, continua ocupando um lugar privilegiado na esfera pública e possui soberania na esfera privada. Menciona-se que, neste estudo, não se questionou sobre valores referentes à renda familiar mensal, devido ao entendimento dos/as autores/as de que essa informação pode ser compreendida como "algo sigiloso" e "íntimo da família", evitando, deste modo, causar possíveis constrangimentos aos/às profissionais do lar entrevistados/as.

Devido ao exercício de uma profissão não remunerada no âmbito doméstico, a maioria dos/as entrevistados/as mencionou que o seu poder de compra foi comprometido em partes (Valéria, Eduardo) ou totalmente comprometido (Bruna, Caio, Cristina, Heloísa, Eliana, Diego, Rosa), o que não é bem visto por eles/as, pois traz recordações negativas, como mostram as unidades de significado a seguir. No entanto, as entrevistadas Cristina e Eliana apontaram como aspecto positivo o fato de agora terem de controlar suas compras, demonstrando não serem conscientes da relação de poder exercida pelo marido, que detém a totalidade da renda da família e centraliza todas as decisões a este respeito. Por unanimidade, os/as profissionais do lar entrevistados/as declararam que devem consultar o/a cônjuge antes da aquisição de qualquer produto e/ou serviço para si e/ou para a família. 
"É complicado de eu querer comprar uma coisa e chegar e dizer pro marido: 'Me dá o dinheiro que eu preciso de tal coisa que eu quero'. Não é assim. (balançando a cabeça negativamente)" (Bruna:9:1);

"O meu poder de compra, poder aquisitivo, foi comprometido, é morto. (...) Antes de comprar qualquer coisa eu tenho que consultar a esposa e fazer a conta." (Caio:9:2);

"Agora eu dependo do marido, mas é bom porque daí eu controlo as compras, agora, né?" (Cristina:9:1);

"Tudo o que a gente precisa comprar tem que pedir pro marido, se ele concorda, se dá pra comprar, a não ser a comida e as coisas do dia a dia. (...) Vejo isso como algo negativo, porque eu não tenho nenhum poder de decisão em casa por não ter o meu próprio dinheiro. (feição de tristeza)" (Heloísa:9:2);

"Eu era muito de comprar, mas agora eu não posso e tá, isso serve pra eu me controlar um pouco." (Eliana:9:1);

"No começo, eu me sentia bastante desconfortável quando a gente saia e tal. Eu sempre trabalhei, eu sempre gostei de comprar as coisas, dar presente, ou comprar algo pra mim, entendeu?" (Diego:9:1).

Quanto à atividade complementar de renda, essa é realizada por alguns/mas profissionais do lar entrevistados/as e aceita por suas famílias, pois constitui uma forma de obtenção de ingressos monetários e de aquisição de produtos e/ou serviços. Dentre as atividades complementares de renda, Bruna e Denise realizam "costuras de roupas"; Valéria realiza "venda de bijuterias, semijoias, lingeries e por catálogo"; Rosa e Eduardo realizam "venda de artesanato"; e Márcia realiza "decoração de festas infantis". Observase que essas atividades são realizadas, na maioria, por mulheres, brancas e pretas, pertencentes às classes sociais baixa e média (Tabela 1). Para Bruna, Valéria e Márcia, essas atividades são realizadas com o objetivo de complementar a renda familiar mensal; já para Denise, Rosa e Eduardo, realizá-las significa um passatempo, um hobby, uma ocupação para as horas de lazer.

Ainda que a informação sobre os ingressos monetários auferidos pelos/as profissionais do lar não tenha sido questionada durante as entrevistas, nota-se que eles/as se beneficiam de uma posição de autonomia econômica frente aos/às seus/suas cônjuges para pequenos gastos, evitando que solicitem dinheiro e, especialmente no caso das mulheres, elevando seu poder de decisão no âmbito doméstico. Isso fica explícito nas unidades de significado apresentadas a seguir.

"Eu uso a renda pra família e pra gastos pessoais." (Bruna:9:3);

"Entra alguma coisinha aqui, outra ali, mas nada absurdo, é uma coisinha bem complementar mesmo. (risos) Eu faço mais por hobby mesmo." (Denise:9:3);

"Não é muita renda, mas me ajuda a ficar um pouco independente, não totalmente dependente do marido." (Valéria:9:2); 
Revista Punto Género N ․ํ 15. Junio de 2021

ISSN 0719-0417 / 47-69

"É um dinheiro meu, que eu gasto com o que eu quero, não tendo que ficar pedindo e gastando dinheiro do marido." (Rosa:9:3).

As unidades de significado anteriormente apresentadas indicam que a renda ainda que seja relativamente pequena - oriunda da atividade complementar tende a empoderar as mulheres. No entanto, ela não possui o poder de modificar por si a situação da dependência econômica do marido. Segundo Bruna, Denise, Valéria, Rosa, Márcia e Eduardo, o acesso à renda não gerou conflitos familiares, pois também a utilizam para adquirir alimentos, produtos e/ou serviços que beneficiam todos os membros da família. Seus discursos revelam que a realização de atividade complementar de renda é bastante valorizada, uma vez que ter seu próprio dinheiro significa a possibilidade de possuir voz ativa na esfera privada e autonomia no uso do dinheiro, e de circular na esfera pública. Além disso, Bruna, Caio, Cristina e Valéria, entrevistados/as pertencentes à classe social baixa, mencionaram não receber auxílio de políticas de transferência de renda (Bolsa Família, por exemplo). Caso recebessem, esse auxílio poderia contribuir enquanto complemento de renda familiar mensal.

Questionou-se aos/as profissionais do lar se realizam contribuições mensais ao Regime Geral de Previdência Social, visando possuir benefícios previdenciários, principalmente a aposentadoria. Dentre os/as entrevistados/as, apenas Denise e Márcia realizam contribuições mensais para a previdência social, enquadradas nas categorias segurado facultativo (como dona de casa) e contribuinte individual (como autônoma), respectivamente. Eliana, Diego, Rosa e Eduardo possuem o interesse em voltar a realizar as contribuições mensais visando à aposentadoria; Bruna e Pâmela não desejam continuar contribuindo mensalmente, devido às ameaçadoras propostas de reforma previdenciária e ao descontentamento com o atual governo brasileiro; e Caio, Cristina e Valéria não realizam as contribuições mensais, devido às condições econômicas familiares. Esses aspectos podem ser observados nas seguintes unidades de significado.

“Já realizei. Com este nosso atual governo... (alguns segundos pensando) Hoje eu não realizo porque eu não quero.” (Pâmela:10:1);

"No momento, eu não tenho remuneração nenhuma e não tenho como pagar, mas se pelo menos eu tivesse trabalhando, eu pagaria o valor mínimo da guia. Isso [o não pagamento da guia] prejudica um monte a pessoa que quer se aposentar." (Caio:10:1);

"Várias vezes se falou sobre meu marido pagar para que no futuro eu pudesse me aposentar, mas sempre ficou apenas no falar, nunca se pagou nada, nunca se fez nada a esse respeito." (Heloísa:10:3);

"Eu contribuo como dona de casa, tanto aqui em Livramento quanto em Rivera. Recentemente, tive um problema na gravidez, e eu tô utilizando o auxílio-doença." (Denise:10:1);

"É uma coisa que eu me arrependo. (pensando) Ou não, né? Do jeito que está o Brasil hoje... (risos). Eu não paguei, e, olha, não sei te dizer por que não paguei. (...) Eu adiei, adiei, e só me dei conta depois da importância que é pagar." (Rosa:10:1). 
A decisão de contribuir para a previdência social é pessoal, sendo uma forma de o indivíduo estar incluído em um sistema de seguridade social que garante benefícios previdenciários. No entanto, os/as entrevistados/as são profissionais do lar, trabalham no âmbito doméstico e não possuem remuneração, com exceção de alguns/mas que realizam atividades complementares de renda. Certamente, essa decisão deverá envolver o/a cônjuge, que possivelmente será o responsável pelo pagamento mensal da Guia da Previdência Social.

Caso busquem proteção social através da contribuição voluntária ao Regime Geral da Previdência Social, os/as profissionais do lar entrevistados/as podem se enquadrar no segurado facultativo ou no facultativo de baixa renda, pagando uma alíquota de $11,0 \%$ e 5,0\% sobre o valor do salário-mínimo nacional vigente, respectivamente (MPAS, 2016). Possivelmente, o valor mensal da Guia da Previdência Social pode ser considerado pequeno para aqueles/as entrevistados/as de classe social média. No entanto, para os/as entrevistados/as de classe social baixa, realizar o pagamento da guia pode ser dificultoso, representando um ônus no orçamento familiar mensal e podendo, inclusive, esse aporte fazer falta à família no mês para suprir alguma necessidade.

Por fim, menciona-se que a desvalorização das pessoas que realizam o trabalho doméstico não remunerado é histórica na legislação brasileira. Esse trabalho foi regulamentado somente para fins previdenciários em 1991, pela Lei no 8.213, o que implica dizer que até aquele ano os mais básicos direitos sociais eram negados a essas pessoas. De fato, isso representa um avanço no campo jurídico, mas é necessário avançar ainda mais. A legislação constitui uma maneira de reconhecer, visibilizar e valorizar o trabalho doméstico não remunerado e a pessoa que o realiza, especialmente a mulher, sendo capaz de promover reflexões sobre a importância desse trabalho para o bem-estar dos membros da família e da sociedade e para a reprodução do capital.

\section{Comentários finais}

Apesar do esforço de uma argumentação em prol da valorização das pessoas que assumem os cuidados da casa e da família, procurando atribuir a noção de profissão também ao trabalho reprodutivo, os resultados encontrados continuam a demonstrar uma reprodução de um modelo de trabalho invisível, desvalorizado e não reconhecido. Infelizmente a resposta para a pergunta trazida no título deste estudo aponta para isso. $O$ estudo mostrou um quadro de desigualdades entre os homens e as mulheres entrevistados/as em relação ao abandono de funções remuneradas no mercado de trabalho para o exercício da profissão do lar, para a realização do trabalho reprodutivo na esfera privada, sendo esse quadro mais intensamente vivido pelas mulheres. De forma geral, a saída do mercado de trabalho pelos/as profissionais do lar, por um lado, possibilitou a reprodução social, a realização de atividades de cuidados, especialmente ligadas aos/às filhos/as; entretanto, por outro lado, agravou a situação de dependência econômica, sobretudo para as mulheres. 
Ao interrogar as condições que causaram a adesão ao enclausuramento ao lar pelos homens e pelas mulheres entrevistadas, observou-se que, em alguns casos foi por escolha, em outros, por imposição. Entretanto, as normas e práticas sociais dificultam às mulheres entrevistadas serem autônomas na condução de suas vidas, em suas posições e escolhas de sujeitos. A pressão sociocultural sobre elas fez com que ficassem em casa, na esfera privada, realizando os afazeres domésticos e as atividades de cuidados, encarando a situação como definitiva, acreditando ser seu lugar e dever; sobre eles, fazia com que se sentissem desconfortáveis em estar em casa, que buscassem realizar atividades remuneradas fora do lar, na esfera pública, encarando a situação como temporária. Reproduzindo um estereótipo de menosprezo pelo trabalho reprodutivo.

Percebeu-se que a maternidade constitui um ponto importante do projeto de vida das mulheres entrevistadas, constituindo um fator que determinou o egresso delas do mercado de trabalho. Há uma pressão sociocultural sobre elas para que criem e eduquem seus/suas filhos/as, fazendo com que se sintam culpadas quando não podem. Como se não bastasse, segundo o pensamento machista, ser "natural" que as mulheres se dediquem aos/às filhos/as, que permaneçam em casa. Isso fica mais evidente quando se observam os dados coletados durante a pandemia da COVID-19, que demonstram que as mulheres além de perder espaço no mercado de trabalho estão ainda mais sobrecarregadas com as atividades domésticas, uma vez que atualmente as escolas estão fechadas e muitas destas mulheres desdobram-se entre o trabalho remunerado e 0 trabalho doméstico (PNAD Contínua/IBGE, 2021).

O trabalho doméstico é percebido pelos/as profissionais do lar, especialmente por elas, como uma atividade que, além de não remunerada, é invisível e desvalorizada na esfera privada, tanto pela família quanto pela sociedade. As razões para isso estão profundamente relacionadas com o papel da mulher fundamentado na sociedade patriarcal e com a noção de trabalho elaborada pelo sistema capitalista. O manto de invisibilidade que recobre o trabalho doméstico não remunerado, o trabalho reprodutivo, não permite que ele seja contabilizado no Produto Interno Bruto do Brasil, apesar dos esforços acadêmicos para que essa situação se altere (Melo, Considera \& Sabbato, 2016), o que acaba reforçando ainda mais a discriminação dos indivíduos, sobretudo mulheres, e a noção de não trabalho pela família e pela sociedade.

Enquanto o Sistema de Contas Nacionais do Brasil possuir como orientação a produção capitalista industrial, o contexto familiar e o trabalho doméstico não remunerado continuarão ocultos, escondidos. Ao ser valorado, esse trabalho terá seu valor reconhecido, e assim passará a ser valorizado pelo indivíduo, pela família e pela sociedade brasileira. É um passo importante, em conjunto com esforços educacionais e conscientização social, para acabar com o pensamento sociocultural falso de considerar o trabalho doméstico não remunerado como não-trabalho. É trabalho, sim! Por essas razões, ampliar as discussões acadêmicas, metodológicas, sociais, políticas, sobre os aspectos do trabalho doméstico não remunerado e as maneiras de valorizá-lo nas sociedades é urgente e importante. 
A educação é um aspecto importante que merece algumas considerações. Os discursos da maioria dos homens e das mulheres entrevistados/as revelaram indícios de uma educação conservadora, perpetuando os tradicionais papéis sociais, os modos de pensar e de agir, e reproduzindo estereótipos e desigualdades de gênero: eles foram educados para confirmar a ideia da superioridade de seu sexo, como dominadores da natureza, da família e da sociedade, para permanecerem na esfera pública; e elas para corresponder às concepções da sua natureza, vinculadas às funções naturais da sexualidade e da reprodução, para permanecerem dentro da esfera privada. Por outro lado, uma minoria dos homens e das mulheres entrevistados/as mostraram sinais de uma educação menos conservadora, visto que compartilham de forma mais equânime a responsabilidade pela realização dos afazeres domésticos e das atividades de cuidados infantis. No caminho em direção à igualdade entre os gêneros, é possível enxergar, nesses casos, luz através da bruma.

Há muito ainda para saber sobre os questionamentos levantados neste estudo. Torna-se necessário avançar mais de modo empírico e teórico no conhecimento sobre eles. Por isso, incentiva-se estudos futuros que ampliem os espaços de pesquisa (cidades/estados/países) e que continuem as discussões aqui iniciadas. Como outras sugestões de estudos futuros, indica-se: pesquisar homens e masculinidades, analisando o envolvimento deles na esfera privada e a (des)igualdade entre os sexos na vida doméstica e familiar, bem como investigar quais marcadores sociais têm efeito sobre a participação masculina no trabalho doméstico, no cuidado com os/as filhos/as pequenos/as e na família.

\section{Referências}

Batthyány, Karina, Genta, Natalia \& Perrotta, Valentina. (2017): "El aporte de las familias y las mujeres a los cuidados no remunerados en salud en Uruguay". Revista Estudos Feministas, Florianópolis, v. 25, n. 1, p. 187-213, jan./abr. http://dx.doi.org/10.1590/1806-9584.2017v25n1p187

Bezerra, Sirlene \& Vieira, Adriane. (2013): "Dilemas e desafios vividos por mulheres que migraram em função do trabalho do cônjuge". Revista de Administração Mackenzie, São Paulo, v. 14, n. 6, p. 216-243, Edição Especial, nov./dez. https://doi.org/10.1590/S1678-69712013000600010

Bidarte, Marcos. (2018): "Profissão do lar: imposição ou escolha?" Dissertação Universidade Federal do Pampa, Mestrado em Administração, Santana do Livramento: http://dspace.unipampa.edu.br:8080/jspui/handle/riu/2962

Unipampa.

Bidarte, Marcos, Fleck, Carolina \& Mello, Elena. (2018): "Para o lar: as mulheres que deixaram o mercado de trabalho para se dedicarem à casa e à família". Revista Gênero, Niterói, v. 19, n. 1, p. 6-24, jul./dez. https://doi.org/10.22409/rg.v19i1.1218 
Revista Punto Género N ․ํ 15. Junio de 2021

ISSN 0719-0417 / 47-69

Bidarte, Marcos \& Fleck, Carolina. (2019): "Evolução da Participação Feminina e Masculina em Afazeres Domésticos no Brasil". Oikos: Família e Sociedade em Debate, Viçosa, v. 30, n. 1, p. 87-103, jul./dez. https://doi.org/10.31423/oikos.v30i1.8282

Bruschini, Cristina. (1985): “Mulher e trabalho: uma avaliação da década da mulher”. São Paulo: Nobel, 1985.

Bruschini, Cristina. (1994): "O trabalho da mulher brasileira nas décadas recentes". Revista Estudos Feministas, Florianópolis, Número Especial - Colóquio Internacional França, Brasil e Quebec, p. 179-199.

Bruschini, Cristina. (1995): "Maternidade e trabalho feminino: sinalizando tendências". In: Family Health International (FHI): Reflexões sobre gênero e fecundidade no Brasil. Projeto de Estudos da Mulher: Brasil, p. 29-53, Research Triangle Park: FHI.

Bruschini, Cristina. (1996): "Desigualdades de gênero no mercado de trabalho brasileiro: o trabalho da mulher no Brasil e nas regiões nordeste e sudeste na década de oitenta". In: Ligocki, Malo \& Libardoni, Marlene (Coords.): Discriminação positiva, ações afirmativas: em busca da igualdade. 2. ed., p. 87-118, São Paulo: CFEMEA/Elas.

Bruschini, Cristina. (1998): “Trabalho das mulheres e mudanças no período 1985-1995". 78p., Textos FCC, n. 17, São Paulo: FCC/DPE.

Bruschini, Cristina. (2006): "Trabalho doméstico: inatividade econômica ou trabalho nãoremunerado?" Revista Brasileira de Estudos de População, São Paulo, v. 23, n. 2, p. 331-353, jul./dez. http://dx.doi.org/10.1590/S0102$\underline{30982006000200009}$

Bruschini, Cristina. (2007): “Trabalho e gênero no Brasil nos últimos dez anos". Cadernos de Pesquisa, São Paulo, v. 37, n. 132, p. 537-572.

Bruschini, Cristina, Lombardi, Rosa, Miglioranza, Cristiano \& Ricoldi, Arlene. (2011): "Trabalho, renda e políticas sociais: avanços e desafios". In: Barsted, Leila \& Pitanguy, Jacqueline. (Orgs.): O Progresso das Mulheres no Brasil 20032010. Cap. 7, p. 142-177. Rio de Janeiro: CEPia; Brasília: ONU Mulheres.

Caetano-da-Silva, Mara. (2013): "O Processo de Inserção da Mulher no Mercado de Trabalho Angolano: Estratégias, Trajectórias e Contextos Socioprofissionais". 135 f. Dissertação (Mestrado em Serviço Social e Políticas Sociais), Universidade Lusófona de Humanidades e Tecnologias, Lisboa.

Calderón, Yannet \& Campos-Ríos, Guillermo. (2013): “Las Mujeres Jóvenes en México: ¿Estudian o Trabajan?". Última década, Santiago, v. 21, n. 39, p. 63-83, dec. http://dx.doi.org/10.4067/S0718-22362013000200004

Carrasco, Cristina. (2005): "Tiempo de trabajo, tiempo de vida. Las desigualdades de género en el uso del tempo". In: Aguirre, Rosario, Sainz, Cristina \& Carrasco, 
Revista Punto Género N ․ํ 15. Junio de 2021

ISSN 0719-0417 / 47-69

Cristina. (Orgs.) El tiempo, los tiempos, una vara de desigualdad. Serie Mujer y Desarrollo, n. 65. Santiago de Chile: CEPAL: Unidad Mujer y Desarrollo.

Chovwen, Catherine. (2007): "Barriers to acceptance, satisfaction and career growth: Implications for career development and retention of women in selected male occupations in Nigeria". Women in Management Review, v. 22, n. 1, p. 68-78. https://doi.org/10.1108/09649420710726238

Costa, Albertina. (2014): "Rotinas de mulher". In: Ávila, Maria; Ferreira, Verônica. (Orgs): Trabalho remunerado e trabalho doméstico no cotidiano das mulheres. p. 712, Fortaleza: SOS CORPO Instituto Feminista para a Democracia/Instituto Patrícia Galvão.

Creswell, John. (2010): "Projeto de pesquisa: métodos qualitativo", quantitativo e misto. 3. ed. Porto Alegre: Artmed.

Flick, Uwe. (2009): “Introdução à pesquisa qualitativa”. 3. ed. Porto Alegre: Artmed.

Funk, Anette, Lang, James \& Osterhaus, Juliane. (2005): "Ending Violence against Women and Girls - Protecting Human Rights: Good Practices for Development Cooperation". Deutsche Gesellschaft für Internationale Zusammenarbeit, Planning and Development Department Governance and Democracy, Eschborn, Germany.

Hewlett, Sylvia \& Luce, Carolyn. (2005): "Off-Ramps and on-ramps: keeping talented women on the road to success". Harvard Business Review, Cambridge, v. 83, n. 3, p. 43-54, mar.

Instituto Brasileiro de Geografia e Estatística - IBGE. (2006): "Síntese de indicadores sociais: 2005”. 330p. Rio de Janeiro: IBGE.

IBGE. (2010): "Síntese de indicadores sociais: uma análise das condições de vida da população brasileira: 2010”. 317p. Rio de Janeiro: IBGE.

IBGE. (2014): "Síntese de indicadores sociais: uma análise das condições de vida da população brasileira: 2014". 214p. Rio de Janeiro: IBGE.

IBGE. (2015): "Síntese de indicadores sociais: uma análise das condições de vida da população brasileira: 2015". 134p. Rio de Janeiro: IBGE.

IBGE. (2016): "Síntese de indicadores sociais: uma análise das condições de vida da população brasileira: 2016". 146p. Rio de Janeiro: IBGE.

IBGE. (2020): “PNAD Contínua: Outras formas de trabalho 2019”. 12p. Rio de Janeiro: IBGE.

IBGE. (2021): "Pesquisa Nacional por Amostra de Domicílios Contínua - Divulgação dos Resultados Trimestrais". Rio de Janeiro: IBGE [On Line]. Disponível em: https://sidra.ibge.gov.br/pesquisa/pnadct/tabelas 
Revista Punto Género N ․ํ 15. Junio de 2021

ISSN 0719-0417 / 47-69

Ituma, Afam \& Simpson, Ruth. (2009): “The 'boundaryless' career and career boundaries: Applying an institutionalist perspective to ICT workers in the context of Nigeria". Human Relations, v. 62, n. 5, p. 727-761. https://doi.org/10.1177\%2F0018726709103456

Kabeer, Naila, Huda, Karishma, Kaur, Sandeep \& Lamhauge, Nicolina. (2012): "Productive safety nets for women in extreme poverty: lessons from pilot projects in India and Pakistan". School of Oriental and African Studies, London: University of London. https://eprints.soas.ac.uk/id/eprint/34270

Kergoat, Danièle. (2003): "Divisão sexual do trabalho e relações sociais de sexo". In: Emílio, Marli et al. (Orgs.) Trabalho e cidadania ativa para as mulheres: desafios para as Políticas Públicas. p. 55-63, São Paulo: Coordenadoria Especial da Mulher.

Madalozzo, Regina, Martins, Sergio \& Shiratori, Ludmila. (2010): "Participação no mercado de trabalho e no mercado doméstico: homens e mulheres têm condições iguais?". Revista Estudos Feministas, Florianópolis, v. 18, n. 2, p. 547-566. http://dx.doi.org/10.1590/S0104-026X2010000200015

Marx, Karl. (1988): “O capital: crítica da economia política”. V. I. São Paulo. Nova Cultural.

Meihy, José \& Ribeiro, Suzana. (2011): "Guia prático de história oral: para empresas, universidades, comunidades, famílias”. São Paulo: Contexto, 2011.

Melo, Hildete \& Castilho, Marta. (2009): “Trabalho reprodutivo no Brasil: quem faz?", Revista Economia Contemporânea, Rio de Janeiro, v. 13, n. 1, p. 135-158, jan./abr. https://doi.org/10.1590/S1415-98482009000100006

Melo, Hildete \& Sabbato, Alberto. (2011): "Trabalhadoras domésticas: eterna ocupação feminina. Até quando?” In: Barsted, Leila \& Pitanguy, Jacqueline. (Orgs.): 0 Progresso das Mulheres no Brasil 2003-2010. Cap. 8, p. 179-185. Rio de Janeiro: CEPia; Brasília: ONU Mulheres.

Melo, Hildete, Considera, Claudio \& Sabbato, Alberto. (2016): "Dez anos de mensuração dos afazeres domésticos no Brasil". In: Fontoura, Natália \& Araújo, Clara. (Orgs.) Uso do tempo e gênero. Cap. 6, 173-188. Rio de Janeiro: UERJ/SPM/IPEA.

Ministério da Previdência e Assistência Social do Brasil - MPAS. (2016): "Inscrição da Previdência Social'. Disponível em: http://www.mpas.gov.br/.

Moraes, Roque \& Galiazzi, Maria. (2011): “Análise textual discursiva”. Ijuí: Editora Unijuí.

Perrot, Michelle. (1988): “Os excluídos da história: operários, mulheres, prisioneiros". Rio de Janeiro, Paz e Terra.

Perticará, Marcela. (2005): "Patrones de inserción laboral feminina". Serie Documentos de investigación, $N^{\circ}$ I-166, Santiago de Chile, Universidad Alberto Hurtado. 
Revista Punto Género N ․ํ 15. Junio de 2021

ISSN 0719-0417 / 47-69

Ricoldi, Arlene. (2010): "A noção de articulação entre trabalho e família e políticas de apoio". Mercado de Trabalho, IPEA, n. 42, p. 37-43, fev.

Rocha-Coutinho, Maria. (2004): "Novas opções, antigos dilemas: mulher, família, carreira e relacionamento no Brasil". Temas em Psicologia da SBP, Ribeirão Preto, v. 12 , n. 1, p 2-17.

Saffioti, Heleieth. (1969): “A mulher na sociedade de classes: mito e realidade". São Paulo: Editora Quatro Artes.

Saffioti, Heleieth. (1987): “O poder do macho”. São Paulo: Moderna.

Santos, Luciana \& Diniz, Gláucia. (2011): "Donas de casa: classes diferentes, experiências desiguais". Psicologia Clínica, Rio de Janeiro, v. 2, n. 23, p. 137149. http://dx.doi.org/10.1590/S0103-56652011000200009

Santos, Luciana \& Diniz, Gláucia. (2018): "Saúde mental de mulheres donas de casa: um olhar feminista-fenomenológico-existencial”. Psicologia Clínica, Rio de Janeiro, v. 30, n. 1, p. 37-59. http://dx.doi.org/10.33208/PC1980-5438v0030n01A02

Sen, Purna. (1998): "Development practice and violence against women". Gender and Development, Great Britain, v. 6, n. 3, p. 7-16.

Soares, Cristiane \& Sabóia, Ana. (2007): "Tempo, trabalho e afazeres domésticos: um estudo com base nos dados da Pesquisa Nacional por Amostra de Domicílios de 2001 e 2005". (Textos para discussão. Diretoria de pesquisas, n. 21), Rio de Janeiro: IBGE, Coordenação de População e Indicadores Sociais.

Soares, Cristiane. (2016): "Os desafios (para as mulheres) do trabalho reprodutivo no Brasil com o processo de envelhecimento populacional". In: Itaboraí, Nathalie, \& Ricoldi, Arlene. (Orgs.) Até onde caminhou a revolução de gênero no Brasil?: implicações demográficas e questões sociais. Belo Horizonte, MG: Associação Brasileira de Estudos Populacionais (ABEP):

Sullerot, Évelyne. (1970): "História e sociologia da mulher no trabalho". [Tradução de Antonio Teles] Rio de Janeiro: Editora Expressão e Cultura.

Sullivan, Sherry \& Mainiero, Lisa. (2008): "Using the Kaleidoscope Career Model to Understand the Changing Patterns of Women's Careers: Designing HRD Programs That Attract and Retain Women". Advances in Developing Human Resources, v. 10, n. 1, p. 32-49, feb. http://dx.doi.org/10.1177/1523422307310110 